Research Paper

\title{
Angiopoietin-like Protein 2 is a Useful Biomarker for Pancreatic Cancer that is Associated with Type 2 Diabetes Mellitus and Inflammation
}

\author{
Takuma Yoshinaga 1, Tatsuyuki Niou 2, Toru Niihara 2, Yoriko Kajiya ${ }^{3}$, Emiko Hori 1, Ayako Tomiyoshi 1 , \\ Erena Tokudome ${ }^{1}$, Hiroto Nishimata ${ }^{2}$, Takayuki Takei ${ }^{4}$, Masahiro Yoshida ${ }^{4}$ \\ 1. Division of Clinical Application, Nanpuh Hospital, Kagoshima, Japan, \\ 2. Gastroenterology, Nanpuh Hospital, Kagoshima, Japan, \\ 3. Department of Radiology, Nanpuh Hospital, Kagoshima, Japan, \\ 4. Department of Chemical Engineering, Graduate School of Science and Engineering, Kagoshima, Japan. \\ $\square$ Corresponding author: Masahiro Yoshida, Ph.D., Department of Chemical Engineering, Graduate School of Science and Engineering, Kagoshima University, \\ 1-21-40 Korimoto, Kagoshima-city, Kagoshima, Japan. Tel; 81-99-285-8526, Email; myoshida@cen.kagoshima-u.ac.jp \\ (c) Ivyspring International Publisher. This is an open access article distributed under the terms of the Creative Commons Attribution (CC BY-NC) license \\ (https://creativecommons.org/licenses/by-nc/4.0/). See http://ivyspring.com/terms for full terms and conditions.
}

Received: 2018.02.06; Accepted: 2018.08.28; Published: 2018.11.25

\begin{abstract}
Pancreatic cancer is one of the tumors with the worst prognosis, with the 5-year survival rate reported to be $6 \%$. The number of patients suffering from pancreatic cancer in recent years has continued to increase dramatically. Carbohydrate antigen 19-9 is an established biomarker of pancreatic cancer, but it does not have sufficient ability to detect pancreatic cancer at an early stage. We focused on angiopoietin-like protein 2 (ANGPTL2), which has been reported to be related to chronic inflammation and Type 2 diabetes mellitus. In this study, whether ANGPTL2 can detect early pancreatic cancer was evaluated. It was found that the concentration of serum ANGPTL2 was significantly higher in pancreatic cancer patients and tumor stage 0 -I patients than in healthy individuals $(5.84 \pm 1.82 \mathrm{ng} / \mathrm{mL}$ vs $3.61 \pm 0.64 \mathrm{ng} / \mathrm{mL} ; P<0.001)(5.68 \pm 0.79 \mathrm{ng} / \mathrm{mL}$ vs $3.61 \pm 0.64$ $\mathrm{ng} / \mathrm{mL} ; P=0.010)$. In addition, the diagnostic capability of serum ANGPTL2 levels for pancreatic cancer was evaluated using receiver operating characteristic (ROC) curve analysis. The area under the ROC curve (AUC) for ANGPTL2 was 0.906 (95\% confidence interval $(\mathrm{Cl}): 0.815-0.997 ; P<$ 0.001 ). To identify the risk factors for pancreatic cancer, multivariate regression models were used. Ten factors were included, and increasing age (odds ratio (OR), $1.318,95 \% \mathrm{Cl}, 1.058-1.642 ; \mathrm{P}=$ 0.014 ) and high ANGPTL2 levels (OR, 22.219, 95\% Cl, 1.962-251.659, $P=0.012$ ) were found to be independent risk factors for pancreatic cancer, with ANGPTL2 having the strongest relationship. In addition, serum ANGPTL2 levels were strongly correlated with inflammatory markers, with blood sugar levels showing the strongest correlation with serum ANGPTL2 levels. In conclusion, this study suggested that an elevated serum ANGPTL2 level has the potential to be a biomarker capable of early detection of pancreatic cancer, and it was correlated with inflammation of the pancreas and the risk of developing diabetes mellitus.
\end{abstract}

Key words: ANGPTL2, biomarker, pancreatic cancer, mellitus, angiogenesis

\section{Introduction}

Pancreatic cancer is one of the tumors with the worst prognosis, with a reported 5-year survival of $6 \%$ [1]. The number of patients suffering from pancreatic cancer in recent years has continued to increase dramatically [2]. Carbohydrate antigen 19-9
(CA19-9) is an established biomarker of pancreatic cancer, but it does not have sufficient ability to detect pancreatic cancer at an early stage [3]. To improve the prognosis of pancreatic cancer patients, there is an urgent need to develop new biomarkers that can 
detect early pancreatic cancer [4]. We focused on angiopoietin-like protein 2 (ANGPTL2), which is a secreted protein that regulates angiogenesis in vivo [5]. In this study, whether ANGPTL2 can detect pancreatic cancer was examined. Angiogenic factors play an important role in tumor growth. In addition, ANGPTL2 has been reported to be a regulator of chronic inflammation [6-10]. Endo et al [9] reported that ANGPTL2 is a potential biomarker of human lung cancer and breast cancer. We previously demonstrated that ANGPTL2 is a clinically useful biomarker in gastric cancer [11] and colorectal cancer [12]. However, the diagnostic usefulness of ANGPTL2 in pancreatic cancer has not yet been investigated.

In humans, ANGPTL2 is also closely related to adiposity and inflammation [13-15], and a recent study reported that elevated serum ANGPTL2 levels in the general population were related to Type 2 diabetes mellitus (DM) and high-sensitivity $C$ reactive protein levels [16]. Obesity increases the risk of pancreatic cancer in DM [17]. Chronic inflammation of the pancreas has been reported to transform into pancreatic cancer [18]. Thus, the aim was to evaluate ANGPTL2, which has been reported as a factor related to obesity, inflammation, and DM, which are risk factors for pancreatic cancer, as a new pancreatic cancer biomarker that can be measured in serum.

In this study, the serum ANGPTL2 concentrations of pancreatic cancer patients and healthy individuals were compared to evaluate the sensitivity and specificity of this protein as a predictive biomarker for pancreatic cancer.

\section{Materials and Methods}

\section{Study population}

The study was approved by the Ethics Committee of Nanpuh Hospital, Kagoshima Kyosaikai, Public Interest Inc. Association, Japan. Clinical examinations were performed according to the principles of the Declaration of Helsinki. Informed consents were obtained from all participants in writing. Serum samples were obtained from 50 participants who attended the clinic at the Nanpuh Hospital between July 2016 and July 2017. Participants were recruited without restrictions on sex and age. The participants whose ANGPTL2 levels were evaluated included 20 patients with pancreatic cancer and 23 healthy individuals (those who underwent a medical check-up, had negative results on positron emission tomography (PET) scanning, and were not notified of abnormalities in other assessments; those who had cancer in the past were excluded). PET was performed using a Discovery ST Elite PET scanner (General Electric Co., Connecticut,
USA). The mean age of the 50 participants (20 male and 30 female) was $61.70 \pm 11.81$ years (mean \pm SD; range, 38-80 years). The patient group included 4 patients diagnosed with tumor stage $0-\mathrm{I}, 8$ patients with tumor stage II, and 8 patients with tumor stage III-IV. Cancer staging was based on routine histopathological analysis and clinical assessment, according to the tumor-node-metastasis (TNM) classification. Tumors were classified according to the recommendations of the guidelines of TNM Classification of Malignant Tumors, 7th Edition.

\section{Measurement of biomarkers and different variables}

The serum concentrations of ANGPTL2 were determined using an ANGPTL2 enzyme-linked immunosorbent assay kit (Immuno-Biological Laboratories, Co., Ltd., Gunma, Japan). Serum concentrations of C-reactive protein (CRP) were determined by latex agglutination using BM6050 (Kyowa-Medex Co., Ltd., Tokyo, Japan) according to the manufacturer's instructions. Concentrations of carcinoembryonic antigen (CEA) and carbohydrate antigen 19-9 (CA19-9) in serum were determined by an electro-chemiluminescence immunoassay using LUMIPULSE G1200 ${ }^{\circledR}$ (Fujirebio, Inc., Tokyo, Japan) according to the manufacturer's instructions. White blood cell count (WBC), red blood cell count (RBC), and hemoglobin $(\mathrm{Hb})$ were measured using an XE-5000 Hematology Analyzer (Sysmex, Co., Hyogo, Japan) according to the manufacturer's instructions. Hemoglobin A1c (HbA1c) was measured using a BioMajesty ${ }^{\circledR}$ JCA-BM6010 (JEOL Ltd., Tokyo, Japan) according to the manufacturer's instructions. Blood sugar (BS), serum total cholesterol (TC), triglyceride (TG), creatinine (Cr), uric acid (UA), and serum amylase (AMY) levels were measured using a BioMajesty ${ }^{\circledR}$ JCA-BM6050 (JEOL Ltd.) according to the manufacturer's instructions.

\section{Statistical analysis}

The results are expressed as means \pm standard deviation (SD). The subjects' characteristics were assessed using Student's $t$-test for continuous variables and the Chi-squared test for categorical variables. These variables included age, sex (male or female), diabetes mellitus (yes or no), hypertension (yes or no), current smoker (yes or no), and blood profiles. Univariate analyses were performed to identify the significant predictors of pancreatic cancer. The significance of differences in serum ANGPTL2 concentrations between pancreatic cancer patients and healthy individuals was analyzed using the rank nonparametric Mann-Whitney $U$ test. In addition, the significance of differences in serum ANGPTL2 
concentrations between individual tumor stages of pancreatic cancer patients and healthy individuals was assessed using one-way analysis of variance (ANOVA). A receiver operating characteristic (ROC) curve was used to evaluate the diagnostic performance of serum ANGPTL2, CEA and CA19-9 in differentiating between pancreatic cancer patients and healthy individuals. Youden's index method was used to determine the optimal cutoff for the ANGPTL2 level for identifying patients with pancreatic cancer [19]. The cutoff value of ANGPTL2 was $4.2 \mathrm{ng} / \mathrm{mL}$. The cutoff value of CA19-9 was 37.0 $\mathrm{U} / \mathrm{mL}$. Data were analyzed using SPSS Version 23 (IBM Co., Armonk, NY, USA). A value of $P<0.05$ was considered significant.

\section{Logistic Regression Models}

Logistic regression (LR) was used to compute the odds ratios of different variables for pancreatic cancer. To develop a good-fit model, all significant variables derived from univariate analyses were entered into the model. Variables significant at 5\% were included in the multiple LR analysis using stepwise backward elimination, with pancreatic cancer as the dependent variable. A $P$ value $<0.05$ was considered significant.

\section{Results}

The baseline clinical characteristics of the 50 subjects are shown in Table 1 . The mean age of pancreatic cancer patients (68.85 \pm 8.01 years) was significantly higher than that of healthy individuals (56.93 \pm 11.61 years; $P<0.001)$. There was a significant difference in history of DM (yes/no) between pancreatic cancer patients $(65.0 \%, 13 / 7)$ and healthy individuals $(10.3 \%, 3 / 27 ; P<0.001)$. There was also a significant difference in the history of HT (yes/no) between pancreatic cancer patients $(45.0 \%, 9 / 11)$ and healthy individuals $(17.2 \%, 5 / 25 ; P=0.035)$. The mean $\mathrm{WBC}$ was $69.37 \pm 37.48 \times 10^{4} / \mu \mathrm{L}$ and $45.47 \pm 10.9$ $\times 10^{4} / \mu \mathrm{L}$, respectively $(P=0.011)$, the mean BS was $151.4 \pm 59.18 \mathrm{~g} / \mathrm{dL}$ and $92.23 \pm 7.78 \mathrm{~g} / \mathrm{dL}$, respectively $(P<0.001)$, and the mean HbA1c was $7.06 \% \pm 2.37 \%$ and $5.6 \% \pm 0.38 \%$, respectively $(P=0.013)$, the mean TG was $116.3 \pm 59.36 \mathrm{mg} / \mathrm{dL}$ and $73.9 \pm 27.21 \mathrm{mg} / \mathrm{dL}$, respectively $(P=0.006)$, in pancreatic patients and healthy individuals.

\section{Serum ANGPTL2 levels are increased in pancreatic cancer patients}

The serum ANGPTL2 level was significantly higher in pancreatic cancer patients $(5.84 \pm 1.82$ $\mathrm{ng} / \mathrm{mL})$ than in healthy individuals $(3.61 \pm 0.64$ $\mathrm{ng} / \mathrm{mL} ; \quad P<0.001)$. We additionally evaluated according to the individual tumor stages of pancreatic cancer patients. The serum ANGPTL2 in stage 0-I, II and III-IV were significantly higher than in healthy individuals $(3.61 \pm 0.64 \mathrm{ng} / \mathrm{mL})$, and respectively $(5.68 \pm 0.79 \mathrm{ng} / \mathrm{mL} ; P=0.010),(5.06 \pm 1.40 \mathrm{ng} / \mathrm{mL} ; P=$ $0.017),(6.70 \pm 2.29 \mathrm{ng} / \mathrm{mL} ; P<0.001)$.

Table 1. Baseline characteristics of the subjects

\begin{tabular}{|c|c|c|c|c|}
\hline Variables & $\begin{array}{l}\text { Pancreatic } \\
\text { cancer patients }\end{array}$ & $\begin{array}{l}\text { Healthy } \\
\text { individuals }\end{array}$ & $\begin{array}{l}\text { Entire } \\
\text { samples }\end{array}$ & P value \\
\hline $\mathbf{N}$ & 20 & 30 & 50 & \\
\hline Age & $68.85 \pm 8.01$ & $56.93 \pm 11.61$ & $61.7 \pm 11.81$ & $<0.001^{*}$ \\
\hline Gender male, \% & $9(45.0 \%)$ & $11(36.7 \%)$ & $20(40.0 \%)$ & 0.556 \\
\hline \multicolumn{5}{|l|}{ Medical history } \\
\hline DM yes, \% & $13(65.0 \%)$ & $3(10.3 \%)$ & $16(32.7 \%)$ & $<0.001^{*}$ \\
\hline HT yes, $\%$ & $9(45.0 \%)$ & $5(17.2 \%)$ & $14(28.6 \%)$ & 0.035 \\
\hline Smoking yes \% & $3(15.0 \%)$ & $5(16.7 \%)$ & $8(16.0 \%)$ & 0.875 \\
\hline \multicolumn{5}{|l|}{ Blood profiles } \\
\hline CRP mg/dL & $1.1 \pm 2.68$ & $0.12 \pm 0.28$ & $0.51 \pm 1.75$ & 0.119 \\
\hline CEA ng/mL & $8.4 \pm 22.39$ & $1.84 \pm 1.05$ & $4.46 \pm 14.34$ & 0.206 \\
\hline CA19-9 U/mL & $\begin{array}{l}9809.08 \pm \\
41305.27\end{array}$ & $12.88 \pm 12.77$ & $\begin{array}{l}3931.36 \pm \\
26173.66\end{array}$ & 0.302 \\
\hline $\mathrm{WBC} \times 10^{4} / \mu \mathrm{L}$ & $69.37 \pm 37.48$ & $45.47 \pm 10.9$ & $55.03 \pm 27.48$ & $0.011^{*}$ \\
\hline $\mathrm{RBC} \times 10^{4} / \mu \mathrm{L}$ & $422.3 \pm 60.71$ & $428.93 \pm 36.26$ & $426.28 \pm 47.1$ & 0.664 \\
\hline $\mathrm{Hb} \mathrm{g} / \mathrm{dL}$ & $12.86 \pm 1.97$ & $13.25 \pm 1.26$ & $13.09 \pm 1.57$ & 0.396 \\
\hline BS mg/dL & $151.4 \pm 59.18$ & $92.23 \pm 7.78$ & $115.9 \pm 47.44$ & $<0.001^{*}$ \\
\hline HbA1c \% & $7.06 \pm 2.37$ & $5.6 \pm 0.38$ & $6.18 \pm 1.67$ & 0.013 \\
\hline TC mg/dL & $186.3 \pm 52.91$ & $199.07 \pm 27.38$ & $193.96 \pm 39.61$ & 0.329 \\
\hline TG mg/dL & $116.3 \pm 59.36$ & $73.9 \pm 27.21$ & $90.86 \pm 47.38$ & $0.006^{*}$ \\
\hline Cr mg/dL & $0.68 \pm 0.18$ & $0.69 \pm 0.17$ & $0.69 \pm 0.17$ & 0.869 \\
\hline UA mg/dL & $4.72 \pm 1.41$ & $4.93 \pm 0.93$ & $4.84 \pm 1.14$ & 0.568 \\
\hline Serum Amy g/dL & $122.15 \pm 155.61$ & $67.57 \pm 18.18$ & $89.4 \pm 101.56$ & 0.135 \\
\hline \multicolumn{5}{|c|}{$\begin{array}{l}\text { * } P \text { value }<0.05 \text {, considered to be statistically significant, present difference of } \\
\text { baseline characteristics between pancreatic cancer patients and healthy individuals. }\end{array}$} \\
\hline \multicolumn{5}{|c|}{$\begin{array}{l}\text { DM: Diabetes mellitus, HT: Hypertension, ANGPTL2: angiopoietin-like protein 2, } \\
\text { CRP: C-reactive protein, CEA: carcinoembryonic antigen, CA19-9: carbohydrate } \\
\text { antigen 19-9, WBC: White blood cell count, RBC: Red blood cells, Hb: Hemoglobin } \\
\text { content, BS: Blood sugar, HbA1c: Hemoglobin A1c, TC: total cholesterol, TG: } \\
\text { triglyceride, Cr: creatinine, UA: uric acid, Amy: amylase. DM and HT had } 1 \text { missing } \\
\text { data. }\end{array}$} \\
\hline
\end{tabular}

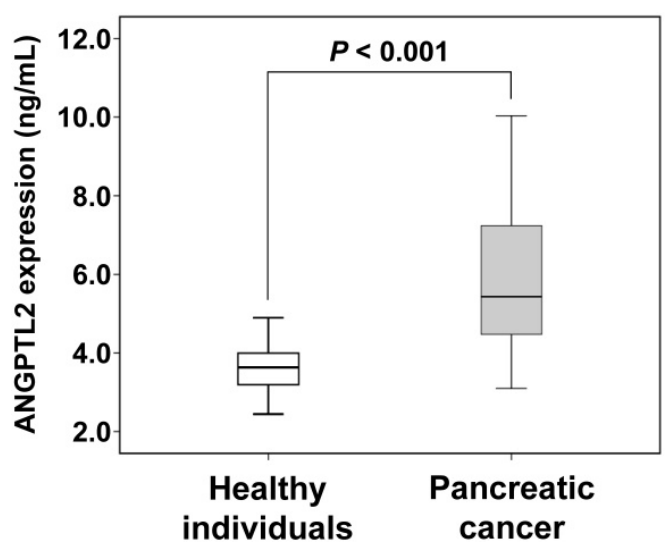

Figure 1. Comparison of ANGPTL2 concentrations between pancreatic cancer patients and healthy individuals. The error bars indicate standard deviation. The serum levels of ANGPTL2 in pancreatic cancer patients $(n=20)$ are higher than those of healthy individuals $(n=30)(5.84 \pm$ $1.82 \mathrm{ng} / \mathrm{mL}$ vs. $3.61 \pm 0.64 \mathrm{ng} / \mathrm{mL} ; P<0.001$ ). ANGPTL2: Angiopoietin-like protein 2

In addition, the diagnostic capability of serum ANGPTL2 levels for pancreatic cancer was evaluated using ROC curve analysis. The area under the ROC curve (AUC) for ANGPTL2 was $0.906(P<0.001,95 \%$ 
confidence interval (CI): 0.815-0.997) (Fig 3). The AUC for CEA and CA19-9 were $0.794(P<0.001,95 \%$ confidence interval (CI): 0.667-0.921) and $0.915(P<$ $0.001,95 \%$ confidence interval (CI): 0.822-1.000) (Fig 3 ). From these results, it showed that the diagnostic ability of pancreatic cancer was as high as CA 19-9. Thus, increasing ANGPTL2 levels proved to be likely to distinguish pancreatic cancer. To compare the sensitivity for pancreatic cancer between ANGPTL2 levels and CA19-9 levels as established tumor markers, the positive rate of cancer was compared between ANGPTL2 and CA19-9. For ANGPTL2 levels, a value of 4.2 or more was considered positive for cancer, while for CA19-9 levels, a level of 37 or more was defined as cancer-positive. In the case of all pancreatic cancer patients $(n=20)$, the sensitivity for pancreatic cancer for ANGPTL2 was $85.0 \%$, while that of CA19-9 was $80.0 \%$. The sensitivity of the combination of ANGPTL 2 and CA19-9 was 100\% (Fig $4 \mathrm{~A})$. In the case of pancreatic cancer patients with stages 0 -I and II $(n=12)$, the sensitivity for pancreatic cancer of ANGPTL2 was $92.0 \%$, while that of CA 19-9 was $83.0 \%$; the sensitivity of the combination of ANGPTL 2 and CA19-9 was 100\% (Fig 4B).

\section{Logistic Regression Analysis}

To identify the factors related to pancreatic cancer, univariate LR analysis was performed in the entire sample, including ANGPTL2, the other blood profiles, and medical history factors. The result indicated that 10 potential risk factors (age, DM, HT, ANGPTL2, CEA, CA19-9, WBC, BS, HbA1c, and TG) were significantly associated with pancreatic cancer $(P<0.05$ for all parameters; Table 2$)$. The odds ratio (OR) for age was 1.128 (95\% CI, 1.044-1.218; $P=0.002)$, and the other odds ratios were: DM, 16.095 (95\%CI, 3.565-72.676; $P<0.001$ ); HT, 3.927 (95\% CI, 1.064-14.49; $P=0.040)$; ANGPTL2, 8.955 (95\% CI, 2.289-35.033; $P=$ 0.002); CEA, 2.227 (95\%CI, 1.286-3.858; $P=0.004)$; CA19-9, 1.066 (95\%CI, 1.016-1.120; $P=0.010) ; \mathrm{WBC}$, 1.082 (95\%CI, 1.025-1.142; $P=0.004)$; BS, $1.325(95 \% \mathrm{CI}$, $1.079-1.626 ; \quad P=0.007) ; \quad \mathrm{HbA1c}, 4.468 \quad(95 \% \mathrm{CI}$, $1.437-13.887 ; P=0.010)$; TG, 1.028 (95\% CI, 1.007-1.048; $P=0.008)$. In the multivariate regression model, all these significant variables identified on univariate analyses were used after stepwise backward elimination of the non-significant variables to obtain the final multivariate regression models, which included age (OR, 1.318, 95\% CI, 1.058-1.642; $P=$ $0.014)$ and ANGPTL2 (OR, 22.219, 95\% CI, 1.962-251.659, $P=0.012$. Based on these data, increasing age and high ANGPTL2 levels were independent risk factors for pancreatic cancer, with ANGPTL2 having the highest OR for pancreatic cancer.
Table 2. Logistic analysis for pancreatic cancer

\begin{tabular}{|c|c|c|c|c|}
\hline \multicolumn{5}{|c|}{ Univariate logistic analysis } \\
\hline Variables & $\mathbf{N}$ & $\beta$ & P value & OR $(95 \% \mathrm{CI})$ \\
\hline Age & 50 & 0.12 & $0.002^{*}$ & $1.128(1.044-1.218)$ \\
\hline Gender & 50 & -0.35 & 0.556 & $0.708(0.224-2.24)$ \\
\hline DM & 49 & 2.78 & $<0.001^{*}$ & $16.095(3.565-72.676)$ \\
\hline HT & 49 & 1.37 & $0.040^{*}$ & 3.927 (1.064-14.49) \\
\hline Smoking & 50 & -0.13 & 0.875 & $0.882(0.186-4.192)$ \\
\hline ANGPTL2 & 50 & 2.19 & $0.002^{*}$ & $8.955(2.289-35.033)$ \\
\hline CRP & 50 & 2.38 & 0.089 & $10.814(0.696-167.956)$ \\
\hline CEA & 50 & 0.80 & $0.004^{*}$ & $2.227(1.286-3.858)$ \\
\hline CA19-9 & 50 & 0.06 & $0.010^{*}$ & $1.066(1.016-1.120)$ \\
\hline WBC & 50 & 0.08 & $0.004^{*}$ & $1.082(1.025-1.142)$ \\
\hline RBC & 50 & -0.00 & 0.623 & $0.997(0.985-1.009)$ \\
\hline $\mathbf{H b}$ & 50 & -0.16 & 0.389 & $0.849(0.584-1.233)$ \\
\hline BS & 50 & 0.28 & $0.007^{*}$ & $1.325(1.079-1.626)$ \\
\hline HbA1c & 50 & 1.50 & $0.010^{*}$ & $4.468(1.437-13.887)$ \\
\hline TC & 50 & -0.01 & 0.266 & $0.991(0.977-1.007)$ \\
\hline TG & 50 & 0.03 & $0.008^{*}$ & $1.028(1.007-1.048)$ \\
\hline $\mathrm{Cr}$ & 50 & -0.29 & 0.866 & $0.751(0.027-20.774)$ \\
\hline UA & 50 & -0.16 & 0.526 & $0.849(0.511-1.410)$ \\
\hline Serum Amy & 50 & 0.02 & 0.050 & $1.022(1.000-1.045)$ \\
\hline \multicolumn{5}{|c|}{ Multivariate logistic analysis } \\
\hline Age & 49 & 0.28 & $0.014^{*}$ & $1.318(1.058-1.642)$ \\
\hline ANGPTL2 & 49 & 3.10 & $0.012^{*}$ & $22.219(1.962-251.659)$ \\
\hline
\end{tabular}

\section{Correlations between the serum ANGPTL2 concentration and different variables}

There were significant correlations between ANGPTL2 and CRP $(\mathrm{r}=0.287, P=0.044)$, WBC $(\mathrm{r}=$ $0.293, P=0.039)$, and BS $(\mathrm{r}=0.551, P<0.001)$ (Table 3$)$. There were no correlations between the ANGPTL2 level and age $(r=0.219, P=0.127)$, CEA $(r=0.265, P=$ $0.062)$, CA19-9 $(\mathrm{r}=0.220, P=0.125), \mathrm{RBC}(\mathrm{r}=-0.234, P$ $=0.102), \mathrm{Hb}(\mathrm{r}=-0.210, P=0.144), \mathrm{HbA1} \mathrm{c}(\mathrm{r}=0.132, P$ $=0.360)$, TC $(\mathrm{r}=-0.195, P=0.174)$, TG $(\mathrm{r}=0.255, P=$ $0.074), \mathrm{Cr}(\mathrm{r}=0.024, P=0.870)$, UA $(\mathrm{r}=0.064, P=$ $0.657)$, and serum Amy $(\mathrm{r}=0.255, P=0.074)$ (Table 3$)$. In this study, serum ANGPTL2 levels were strongly correlated with inflammatory markers (serum CRP and WBC levels), and BS levels were the most strongly correlated with serum ANGPTL2 levels.

\section{Discussion}

To the best of our knowledge, this is the first reported investigation that evaluated the ability of ANGPTL2 to serve as a biomarker of pancreatic cancer. It was demonstrated that serum ANGPTL2 levels were higher in pancreatic cancer patients than in healthy individuals. Furthermore, the results of ROC curve analysis demonstrated that the ability to diagnose pancreatic cancer was high. Furthermore, the sensitivity of ANGPTL2 was equal to or higher than the sensitivity of CA19-9. In addition, combination diagnosis of ANGPTL 2 and CA 19-9 
was diagnosed as cancer with $100 \%$ sensitivity even in early pancreatic cancer. All cancer stages were able to be distinguished with $100 \%$ sensitivity thus that suggests the usefulness of combination diagnosis with CA 19-9. These results suggest that the simultaneous measurement of ANGPTL2 and established biomarkers may reduce the likelihood of overlooking pancreatic cancer.

Table 3. Correlations between the serum ANGPTL2 concentration and different variables

\begin{tabular}{llll}
\hline Variables & $\mathbf{N}$ & Correlation coefficient & P value \\
\hline Age & 50 & 0.219 & 0.127 \\
CRP & 50 & 0.287 & 0.044 \\
CEA & 50 & 0.265 & 0.062 \\
CA19-9 & 50 & 0.220 & 0.125 \\
WBC & 50 & 0.293 & 0.039 \\
RBC & 50 & -0.234 & 0.102 \\
Hb & 50 & -0.210 & 0.144 \\
BS & 50 & 0.551 & $<0.001^{*}$ \\
HbA1c & 50 & 0.132 & 0.360 \\
TC & 50 & -0.195 & 0.174 \\
TG & 50 & 0.255 & 0.074 \\
Cr & 50 & 0.024 & 0.870 \\
UA & 50 & 0.064 & 0.657 \\
Serum Amy & 50 & 0.013 & 0.930 \\
* $P$ value $<$ 0.05, considered to be statistically significant. \\
ANGPTL2: angiopoietin-like protein 2, CRP: C-reactive protein, CEA: \\
carcinoembryonic antigen, CA19-9: carbohydrate antigen 19-9, WBC: White blood \\
cell count, RBC: Red blood cells, Hb: Hemoglobin content, BS: Blood sugar, HbA1c: \\
Hemoglobin A1c, TC: total cholesterol, TG: triglyceride, Cr: creatinine, UA: uric \\
acid, Amy: amylase.
\end{tabular}

Currently, LR analysis can generate excellent models in the field of biomedicine and is widely used [20]. On LR analysis, the factor most strongly related to pancreatic cancer was increasing serum ANGPTL2 levels. These findings suggest that ANGPTL2 is likely to respond to the specific substances of pancreatic cancer. ANGPTL2 was closely related to the risk of pancreatic cancer, and these effects were independent and additive. This study suggested that ANGPTL2 is a useful biomarker for the early detection of pancreatic cancer. This study showed that ANGPTL2 was correlated with inflammatory markers (CRP, WBC). This finding also matches the past research findings [13-15]. In addition, that serum ANGPTL2 levels and blood glucose levels had the strongest correlation also matches the results of a past study [16]. The risk of pancreatic cancer with DM is about twice that without [21], and the results of the present study are important, because ANGPTL2 levels showed a close relationship with DM [14, 22]. Previous studies showed that the risk of type 2 DM increased with enhanced inflammation [23]. The above description is based on the fact that inflammation of adipocytes, adipose tissue, liver, and muscle may cause insulin resistance and beta cell dysfunction [24, 25]. This study was consistent with the mechanism that increasing inflammation induces
DM and enhances the risk of pancreatic cancer. Furthermore, the important point of this study is that the pancreatic cancer in its early stages is accompanied by increased ANGPTL2 levels, before there are increases in inflammatory markers and blood glucose levels. However, the number of cases in this study is not large and there are limits. In future research, we need to increase the number of cases and study. Also, in a previous study, the usefulness of biomarkers of ANGPTL2 of other carcinoma has been reported $[9,11,12]$. Therefore, ANGPTL is not a pancreatic cancer-specific biomarker. From the results of this study, we suggested that in the case of serum ANGPTL2 was high expression, the screening tests including pancreatic cancer was required.

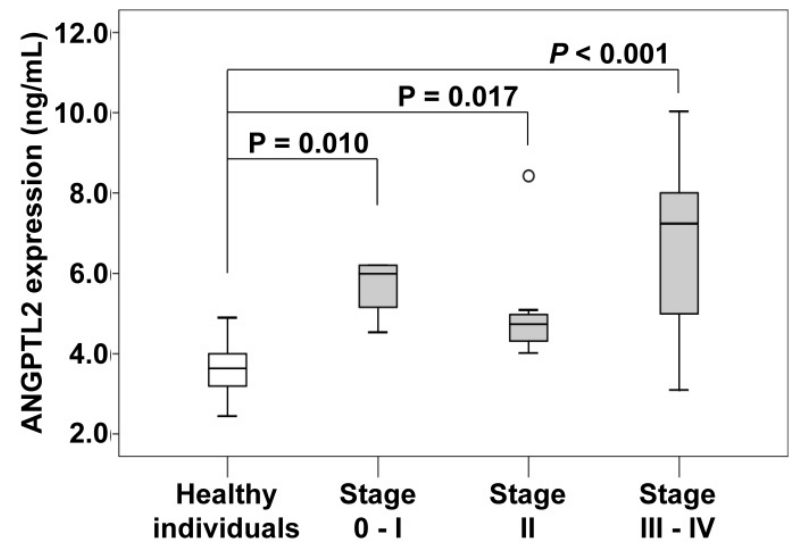

Figure 2. The serum concentration of ANGPTL2 in individual tumor stages in pancreatic cancer patients. The serum concentration of ANGPTL2 of stage $0-I$ pancreatic cancer patients $(5.68 \pm 0.79 \mathrm{ng} / \mathrm{mL})$ is significantly higher than that of healthy individuals $(3.61 \pm 0.64 \mathrm{ng} / \mathrm{mL} ; P=0.010)$. The serum concentration of ANGPTL2 of stage II pancreatic cancer patients $(5.06 \pm 1.40 \mathrm{ng} / \mathrm{mL})$ is significantly higher than that of healthy individuals $(3.61 \pm$ $0.64 \mathrm{ng} / \mathrm{mL} ; P=0.017)$. The serum concentration of ANGPTL2 of stage III-IV pancreatic cancer patients $(6.70 \pm 2.29 \mathrm{ng} / \mathrm{mL})$ is significantly higher than that healthy individuals $(3.61 \pm 0.64 \mathrm{ng} / \mathrm{mL} ; P<0.001)$. ANGPTL2: Angiopoietin-like protein 2

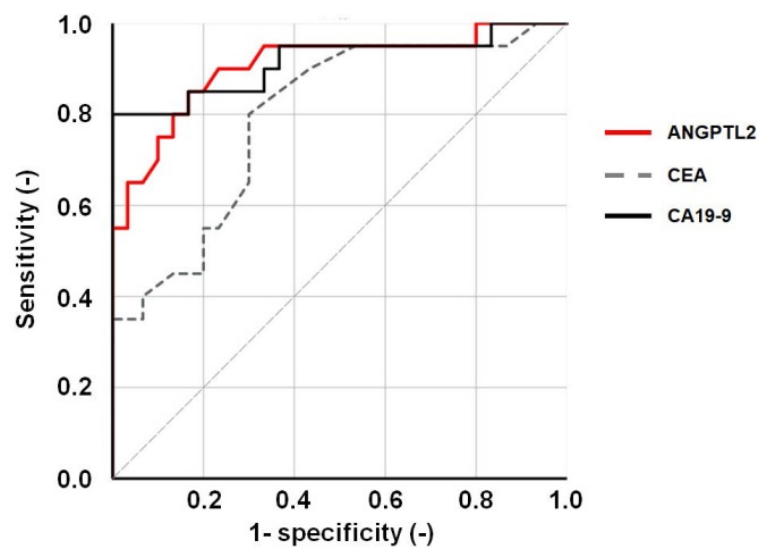

Figure 3. ROC curve of serum ANGPTL2 levels. An ROC curve was constructed to evaluate the diagnostic performance of serum ANGPTL2 levels in differentiating between pancreatic cancer patients $(n=20)$ and healthy individuals $(n=30)$. The area under the ROC curve (AUC) for ANGPTL2 is 0.906 ( $p<0.001,95 \%$ confidence interval $(C l): 0.815-0.997 ; P<0.001)$. And, the AUC for CEA and CA19-9 were $0.794(P<0.001,95 \%$ confidence interval $(\mathrm{Cl})$ : $0.667-0.921)$ and $0.915(P<0.001,95 \%$ confidence interval $(\mathrm{Cl}): 0.822-1.000)$. 

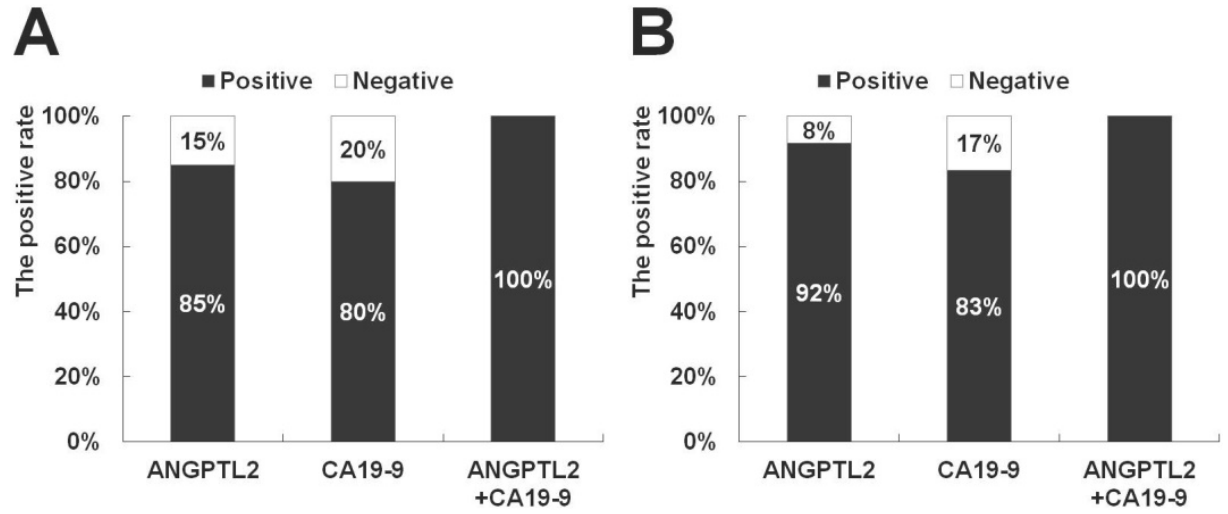

Figure 4. Comparison of the sensitivity for pancreatic cancer patients between ANGPTL2 levels and CA19-9 levels. (A) In the case of all pancreatic cancer patients $(n=20)$, the sensitivity for pancreatic cancer of ANGPTL2 is $85.0 \%$, and that of CA $19-9$ is $80.0 \%$. The sensitivity of the combination of ANGPTL 2 and CA19-9 is $100 \%$. (B) In the case of pancreatic cancer patients with stages $0-\mathrm{I}$ and II $(n=12)$, the sensitivity for pancreatic cancer of ANGPTL2 is $92.0 \%$, and that of CA $19-9$ is $83.0 \%$. The sensitivity of the combination of ANGPTL 2 and CA19-9 is $100 \%$. The cutoff value of ANGPTL2 is $4.2 \mathrm{ng} / \mathrm{mL}$, and the cutoff value of CA19-9 is $37.0 \mathrm{U} / \mathrm{mL}$. ANGPTL2: Angiopoietin-like protein 2, CA19-9: carbohydrate antigen 19-9.

In conclusion, this study suggests that the presence of elevated serum levels of ANGPTL2, which is correlated with inflammation of the pancreas and the risk of developing DM, has the potential to be a biomarker capable of early detection of new-onset pancreatic cancer.

\section{Acknowledgments}

The authors appreciate the support of the Department of Gastroenterology and the Clinical Laboratory and Total Quality Management Division of Nanpuh Hospital.

\section{Ethics}

This study was approved by the Ethics Committee of Nanpuh Hospital, Kagoshima, Japan.

\section{Competing Interests}

The authors have declared that no competing interest exists.

\section{References}

1. Siegel R, Ma J, Zou Z, Jemal A. Cancer statistics, 2014. CA Cancer J Clin. 2014; 64: 9-29.

2. Yadav D, Lowenfels $\mathrm{AB}$. The epidemiology of pancreatitis and pancreatic cancer. Gastroenterology. 2013; 144: 1252-1261.

3. Ballehaninna UK, Chamberlain RS. Serum CA 19-9 as a Biomarker for Pancreatic Cancer-A Comprehensive Review. Indian J Surg Oncol. 2011; 2: 88-100.

4. Chang MC, Wong JM, Chang YT. Screening and early detection of pancreatic cancer in high risk population. World J Gastroenterol. 2014; 20: 2358-2364.

5. Hato T, Tabata M, Oike Y. The role of angiopoietin-like proteins in angiogenesis and metabolism. Trends Cardiovasc Med 2008; 18: 6-14.

6. Tabata M, Kadomatsu T, Fukuhara S, Miyata K, Ito Y, Endo M, et al. Angiopoietin-like protein 2 promotes chronic adipose tissue inflammation and obesity-related systemic insulin resistance. Cell Metab. 2009; 10:178-188.

7. Kadomatsu T, Tabata M, Oike Y. Angiopoietin-like proteins: emerging targets for treatment of obesity and related metabolic diseases. FEBS J. 2011; 278: 559-564.

8. Aoi J, Endo M, Kadomatsu T, Miyata K, Nakano M, Horiguchi H, et al. Angiopoietin-like protein 2 is an important facilitator of inflammatory carcinogenesis and metastasis. Cancer Res. 2011; 71: 7502-7512.

9. Endo M, Nakano M, Kadomatsu T, Fukuhara S, Kuroda H, Mikami S, et al. Tumor cell-derived angiopoietin-like protein ANGPTL2 is a critical driver of metastasis. Cancer Res 2012; 72: 1784-1794.
10. Okada T, Tsukano H, Endo M, Tabata M, Miyata K, Kadomatsu T, et al. Synoviocyte-derived angiopoietin-like protein 2 contributes to synovial chronic inflammation in rheumatoid arthritis. Am J Pathol. 2010; 176: 2309-2319.

11. Yoshinaga $T$, Shigemitsu $T$, Nishimata $H$, Takei $T$, Yoshida M. Angiopoietin-like protein 2 is a potential biomarker for gastric cancer. Mol Med Rep. 2015; 11: 2653-2658.

12. Yoshinaga T, Shigemitsu T, Nishimata H, Kitazono M, Hori E, Tomiyoshi A, et al. Angiopoietin-like protein 2 as a potential biomarker for colorectal cancer. Mol Clin Oncol 2015; 3:1080-1084.

13. Sasaki Y, Ohta M, Desai D, Figueiredo JL, Whelan MC, Sugano T, et al. Angiopoietin Like Protein 2 (ANGPTL2) Promotes Adipose Tissue Macrophage and $\mathrm{T}$ lymphocyte Accumulation and Leads to Insulin Resistance. PLoS One. 2015; 10:e0131176.

14. Jung CH, Lee WJ, Lee MJ, Kang YM, Jang JE, Leem J, et al. Association of serum angiopoietin-like protein 2 with carotid intima-media thickness in subjects with type 2 diabetes. Cardiovasc Diabetol. 2015; 14: 35.

15. Umikawa M, Umikawa A, Asato T, Takei K, Matsuzaki G, Kariya K, et al. Angiopoietin-like protein 2 induces proinflammatory responses in peritoneal cells. Biochem Biophys Res Commun. 2015; 467: 235-241.

16. Doi Y, Ninomiya T, Hirakawa Y, Takahashi O, Mukai N, Hata J, et al. Angiopoietin-like protein 2 and risk of type 2 diabetes in a general Japanese population: the Hisayama study. Diabetes Care. 2013; 36:98-100.

17. Meinhold CL, Berrington de Gonzalez A, Albanes D, Weinstein SJ, Taylor PR, Virtamo J, et al. Predictors of fasting serum insulin and glucose and the risk of pancreatic cancer in smokers. Cancer Causes Control. 2009; 20: 681-690.

18. Dhar P, Kalghatgi S, Saraf V. Pancreatic cancer in chronic pancreatitis. Indian J Surg Oncol. 2015; 6:57-62.

19. YOUDEN WJ. Index for rating diagnostic tests. Cancer. 1950; 3:32-35.

20. Chen ZY, Liu JH, Liang K, Liang WX, Ma SH, Zeng GJ, et al. The diagnostic value of a multivariate logistic regression analysis model with transvaginal power Doppler ultrasonography for the prediction of ectopic pregnancy. J Int Med Res. 2012; 40: 184-193.

21. Ben $Q, X u$ M, Ning X, Liu J, Hong S, Huang W, et al. Diabetes mellitus and risk of pancreatic cancer: A meta-analysis of cohort studies. Eur J Cancer 2011; 47: 1928-1937.

22. Pickup JC, Mattock MB, Chusney GD, Burt D. NIDDM as a disease of the innate immune system: association of acute-phase reactants and interleukin-6 with metabolic syndrome X. Diabetologia. 1997; 40: 1286-1292.

23. Wang X, Bao W, Liu J, Ouyang YY, Wang D, Rong S, et al. Inflammatory markers and risk of type 2 diabetes: a systematic review and meta-analysis. Diabetes Care 2013; 36: 166-175.

24. Varma V, Yao-Borengasser A, Rasouli N, Nolen GT, Phanavanh B, Starks T, et al. Muscle inflammatory response and insulin resistance: synergistic interaction between macrophages and fatty acids leads to impaired insulin action. Am J Physiol Endocrinol Metab. 2009; 296: E1300-10.

25. Shoelson SE, Lee J, Goldfine AB. Inflammation and insulin resistance.. J Clin Invest 2006; 116: 1793-1801. 